\title{
Modernidad, globalización \\ y la emergencia de la comunicación
}

Margarita Reyna Ruiz'

El PRESENTE ENSAYo intenta reflexionar sobre las condiciones que hicieron de la comunicación una práctica social, al tiempo que un factor central en la edificación de las sociedades modernas. Pero, ¿por qué sería importante regresar al concepto de modernidad en este momento donde las nociones claves en la descripción del mundo parecen ser la globalización, el mercado las interconexiones y los flujos?

La comunicación se considera ahora una tecnología, un sistema de conexión que parece llevar al máximo la idea macluhiana de "el medio es el mensaje". En esta percepción, sin embargo, la comunicación parece reinventarse olvidando que en la génesis de su versión globalizada está la constitución de una práctica social cuya eficacia histórica ha sido la de haberse convertido en dispositivo de legitimación y de integración del proceso que la potenció: la modernidad.

Trataré de mostrar en este ensayo cómo la evolución y transformación de un saber práctico en un campo profesional, y luego, en un saber teórico que pretende incidir como ingeniería social en los procesos de cambio y reproducción de las sociedades, es en parte consecuencia de las nociones inscritas en el proyecto ilustrado de la modernidad que desemboca en la glorificación de la sociedad de comunicación.

Siguiendo a E. Andión, defino las prácticas de la comunicación como prácticas simbólicas específicas cuyos rasgos se han ido delimitando por su constitución como objeto teórico, lo que posibilitó la identificación de un campo del conocimiento. En esto es particularmente ejemplar el caso de la prensa periódica. También el esfuerzo por neutralizar y reducir la heterogeneidad de la comunicación a sus rasgos más

1. Profesora-investigadora, Departamento de Educación y Comunicación, Universidad Autónoma Metropolitana, Xochimilco. 
homogéneos, para conformar teorías que proclaman su eficacia y potencialidad de control sobre los aspectos simbólicos del poder, aún cuando en ellos se evidencien las contradicciones propias de su condición moderna (Andión, 1995:27).

\section{Modernidad y comunicación}

La comunicación como el proceso de interacción humana que se funda en diversas formas de representación simbólica y cuyo soporte básico es el lenguaje, puede entenderse efectivamente como un cierto tipo de acción social o práctica simbólica. A la comunicación se le ha terminado por ver actualmente como el factor que opera discursivamente en la incesante constitución de sentido de la existencia social de los agentes. No obstante, esto no fue viable sino hasta que se hizo evidente que la incuestionada relación necesaria entre el sígno y la cosa, entre el mundo y su representación por el hombre no es sino una derivación histórica, relativa a sus propias condiciones de enunciación.

Es en la modernidad cuando el "hombre" funda su potencia en su finitud y sus limitaciones. El hombre deja de ser creatura de Dios para hacerse sujeto de sí mismo, y al hacerse sujeto de sí mismo puede hacerse objeto de su transformación a través del lenguaje y la comunicación. "La modernidad comienza con esa idea insólita e inmanejable de un ser que es soberano precisamente porque es esclavo, un ser cuya misma finitud le permite tomar el lugar de Dios" (Dreyfus y Rabinow, 1988:51)

Es pues con el advenimiento de la modernidad que la comunicación, como saber y poder que toma por objeto al propio sujeto y que reformula los modos en que este último se constituye socialmente, se va a ir determinando como un campo. Desde él, se irá instituyendo como un instrumento práctico que se acoplará en los dispositivos técnico-simbólicos de las nuevas y amplias escalas de la producción social de significados.

Sabemos, sin embargo, que hablar de modernidad conlleva sus dificultades. Su definición y caracterización parece a veces una tarea compleja por las diversas descripciones que de ella se han hecho y, por supuesto, por los extensos debates a favor o en contra de las consecuencias históricas de su proceso. ${ }^{2}$

2. El libro La dialéctica de la Ilustración de Horkheimer y Adorno se considera el texto clásico que reflexiona críticamente sobre la modernidad. Habermas en La filosofia de la modernidad emprende una revisión y debate de los principios modernos que tuvo sus repercusiones registradas en el libro Habermas y la modernidad de Bernstein et al., Una mirada comprensiva de la modernidad se presenta en el libro Critica a la modernidad de Touraine, en la que revisa su tesis sobre el retomo del 
Entenderé a la modernidad como la experiencia histórica mediante la cual se construyen y legitiman nuevas formas de percepción y categorización del tiempo y del espacio, nuevas formas de formular al hombre que instituyen una nueva división del mundo social. La entendemos como una experiencia histórica no exenta de tensiones, contradicciones y luchas entre diversas posturas donde se nombra, aprende a decirse a sí misma y donde, en su nombre, el desarrollo social sigue ciertos derroteros, cauces que acabarán por legitimar, para bien o para mal, el principio de organización de la vida individual y colectiva a la razón instrumental (Touraine, 1995:17-105)

Con estas premisas asumo entonces que el devenir de la comunicación forma parte, de hecho, de los complejos proceso económicos, políticos, sociales y culturales que supusieron la formación de una economía de mercado; la conformación del Estado moderno y de la sociedad de masas; la aparición de los nuevos soportes técnicos de producción tanto económica como cultural. Y, por supuesto, la comunicación como pieza clave de las nuevas definiciones y configuraciones de la distribución de los saberes y competencias sociales y culturales que se tradujeron en nuevas formas de clasificación y distinción social de los agentes.

Así, es necesario analizar la emergencia de la comunicación como una región del espacio social donde ciertos agentes luchan por instituir sus fronteras como un campo social diferenciado. ${ }^{3}$ En este campo, la comunicación se construye como objeto de conocimiento y como sistema de prácticas especificas reconocidas y validadas interiormente logrando así su autonomía en relación a las reglas de validación de otros dominios.

Por otra parte, si la modernidad posibilita la comunicación también la hace partícipe de las consecuencias que ella engendra. Los postulados de la modernidad incuban contradicciones que se despliegan en su desarrollo histórico generando soluciones paradójicas en relación a su sentido original. ${ }^{4}$

sujeto. Giddens en Las consecuencias de la modernidad nos ofrece una perspectiva de las instituciones modernas y los desafios a los que se enfrentan en la modernidad tardía.

3. Asumimos en esto la propuesta del sociológo P. Bourdieu, quien nos dice que "Los campos se presentan para la aprehensión sincrónica como espacios estructurados de posiciones (o de puestos) cuyas propiedades dependen de su posición en dichos espacios y pueden analizarse en forma independiente de las características de sus ocupantes... la estructura de un campo es un estado de la relación de fuerzas entre los agentes e instituciones que intervención en la lucha o si ustedes prefieren de la distribución del capital específico que ha sido acumulado durante luchas anteriores y que orientan las estrategias ulteriores" (1990, pp. 135-136).

4. Esta sería la postura de Touraine quien afirma: "Cada uno de los fragmentos estallados de la modernidad lleva en sí la marca de la modernidad y también de su crisis. En nuestra cultura y en nuestra sociedad, todo está marcado por esa ambigüedad. Todo es moderno y antimoderno, hasta el punto de 
En el caso de la comunicación estas contradicciones se expresan en la forma como el desarrollo de su capacidad educativa e incluso democratizadora se constituye en su propia multiplicación desintegradora, es decir, en la fragmentación del universo social que pretendía integrar. Esto se expresa más claramente en la dispersión constelada y nómada que el actual contexto de comunicación generalizada provoca con su fluidez de códigos de identidad, con la aceleración de la circulación de los bienes simbólicos producida por las industrias culturales, y por la vertiginosa dinámica de remisiones y conexiones sostenidas en las redes telemáticas por los “cosmopolitas domésticos" (J. Echeverría, 1995).

A la luz de estas consideraciones se requerirá exponer las condiciones históricas que dan lugar a la comunicación desde su emergencia como práctica simbólica diferenciada hasta su constitución como un campo y las dificultades y paradojas que se derivan de su condición moderna. No obstante, considero que esta tarea es una labor arriesgada en los limites impuestos a la extensión de este ensayo ya que el campo comunicativo es en sí mismo un sistema de prácticas, que no aparecen simultáneamente y cuyo desarrollo es heterogéneo, lo que precisaria un trabajo de explicación más exhaustivo y detallado. Sin embargo, podemos ilustrar con el ejemplo de la emergencia y evolución del campo periodístico los avatares de la comunicación como un saber-hacer y una técnica de poder simbólico.

\section{El campo periodístico}

El caso de la prensa es ejemplar, primero porque permite ver en sus diferentes fases la conformación de las distintas funciones que adquiere la comunicación. Segundo porque precede históricamente a los demás sistemas de comunicación (cine, radio, televisión, etcétera). Puede decirse que la práctica periodística corre paralela a la modernidad, no sólo como su consecuencia, sino también como factor constitutivo de ella, en la medida en que genera un soporte clave en la difusión del proyecto ilustrado, y sostiene la legitimación de una noción de "verdad" que se ancla en la idea de la representación objetiva del lenguaje y de la imagen. Tercero, porque la característica del discurso periodístico de cumplir una función referencial, aún cuando compite con la oferta informativa del radio y la televisión, cobra nueva importan-

que no exageraríamos diciendo que el signo más seguro de la modernidad es el mensaje antimoderno que ella emite" (Touraine, 1994, pp. 102-103). También Adorno "vió como nadie la modernidad cultural en todas sus ambigüedades, tanto posibilidades de desencadenar potenciales estéticos y comunicativos, como la posibilidad de una muerte de la cultura" (Wellmer, 1993, p. 13). 
cia por el carácter de canal de difusión alternativo que se asigna actualmente a los periódicos en las redes telemáticas (Internet). Cuarto, porque la prensa cumplió la función de la oferta de ficción que en algún momento brindó también la radio y que actualmente ofrecen el cine y la televisión. Y quinto, porque la dimensión simbólica, en su capacidad estructuradora, está asociada estrechamente como instrumento con el trabajo social de dominación simbólica, lo que incluye a la prensa en el campo de poder con su función instauradora de sucesivas visiones y divisiones del mundo social.

La emergencia del periodismo como expresión práctica de la comunicación tiene sus antecedentes más inmediatos en los denominados "correos", desarrollados en las primeras fases del capitalismo temprano. ${ }^{5} \mathrm{Sin}$ embargo, no es sino con la introducción de las técnicas de impresión que se extendieron rápidamente durante la segunda mitad del siglo XV, cuando se impulsó de manera decidida la práctica periodística. ${ }^{6}$

En sus comienzos el negocio periodístico estuvo organizado como pequeña industria artesanal y el editor, que normalmente era el dueño del negocio, contaba con ayudantes cuya actividad se limitaba a la organización del tráfico de noticias y su clasificación. No es sino hasta que la información se hace accesible a un mayor número de destinatarios, que se puede hablar del surgimiento de la prensa como práctica simbólica diferenciada. $^{7}$

El momento meramente económico que permitió la emergencia de la prensa, no se dio, desde luego, al margen de las condiciones políticas que supusieron la configuración del Estado moderno. La prensa en este sentido fue fundamental al pasar de ser un simple correo a un espacio de intercambio entre el Estado monárquico en transformación y la creciente burguesía comercial y financiera. Todo ello sitúa a la prensa desde sus inicios en el campo de poder. Así pues, a este momento meramen-

5. El intercambio mercantil requirió de la información regular sobre las novedades y acontecimientos ocurridos en las diversas ciudades donde se operaba comercialmente; información sobre las actividades comerciales, políticas y militares que permitiera el comercio de mercancías a largas distancias, práctica característica de este capitalismo temprano al que se ha hecho referencia (Thompson, 1993: 194). En este sentido, las grandes ciudades comerciales son al mismo tiempo centro de tráfico de noticias cuya permanencia se generó en la medida en que el tráfico de mercancias se generalizó. (Habermas, 1981, p. 50).

6. Las primeras imprentas fueron generalmente empresas de pequeña escala comercial que se dedicaban a la producción de manuscritos de carácter religioso y literario, y a la producción de textos para ser usados en las leyes, medicina y comercio. Además de la impresión de publicaciones de libros y manuscritos, las primeras imprentas produjeron panfletos, periódicos y hojas de noticias de diversos tipos. Las primeras hojas de noticias impresas aparecieron a comienzos del siglo XVI. (Thompson, 1993, p. 192)

7. Los periódicos aparecen ya con cierta regularidad a mediados del siglo XVII, pero no es sino hasta finales de ese siglo, que se puede hablar de que estas publicaciones llegaron a un público más extenso. (Thompson, 1993, p. 193). 
te económico se fue añadiendo uno político que marcaría el surgimiento de la prensa de escritores, y con ello la prensa como práctica pedagógica. ${ }^{8}$

Ya para el siglo xIX la prensa de escritores se vio afectada de manera importante por las crisis económicas y financieras de principios de siglo, lo que obligó a los dueños de los periódicos a adoptar diversas estrategias que evitaran la quiebra y que les permitirá ganar el mercado. Así, se tendió a profesionalizar la actividad ante la necesidad de reorganizar internamente la empresa periodística. ${ }^{9}$

La diversificación del público potencial como consecuencia del aumento de la población y la extensión gradual de la instrucción pública, del mejoramiento de los caminos y del transporte (que facilitó la distribución de los periódicos de las capitales a la provincia), de la posterior incorporación de la prensa rápida (prensa rotativa), así como de la consecuente aparición del telégrafo, teléfono y tipógrafo (que revolucionaron la red de información) posibilitaron que el mercado para los periódicos y los libros impresos se extendiera constantemente. Se generó entonces la necesidad de nuevas formas de financiamiento y difusión. Lo anterior permitió el crecimiento y consolidación del periódico de circulación masiva y el interés de los editores por hacer de esta empresa una actividad lucrativa. ${ }^{10}$

Todo esto trajo consecuencias importantes en la concepción misma de la práctica periodística, y por tanto de la comunicación, al establecerse las condiciones a partir de las cuales se manifestaría una de sus principales contradicciones. Por una parte al favorecer un mercado interno, ajustado todavía a las dimensiones de la

8. En esta prensa de escritores la mayor parte de las veces los editores dueños de los periódicos eran ellos mismos intelectuales, artistas o escritores, y su función consistió en recopilar noticias y artículos dando cabida a los pensadores e intelectuales de la época y permitiendo hacer del conocimiento de la población lectora, aunque todavía restringida, los temas de interés cultural y político. Sobre esto último Habermas señala que "Todavía a comienzos del siglo xvil más de la mitad de la población en Europa vivia en los limites de la supervivencia. La mayor parte de la población era analfabeta y sin recursos para acceder al mercado de productos culturales" (Habermas, 1981, p. 75).

9. Se inserta de esta manera una nueva instancia entre la colección de noticias y su publicación: la redacción, separándose las funciones de publicación que corría a cargo de la redacción y las económicas que terminaron por ser responsabilidad del editor (Habermas, 1981, p. 210). La redacción requirió entonces de personas con un amplio manejo del lenguaje escrito, convirtiendo el trabajo del escritor en un trabajo asalariado. De igual manera aparecen los ilustradores. Los grabados jugarán un papel importante dentro de esta nueva producción en masa en la medida en que se buscará llegar a toda una franja de lectores semialfabetos para quienes los dibujos constituirán un motivo de compra (Kaenel, 1987, p. 35).

10. Los dueños de los periódicos buscaron entonces incrementar la circulación como una manera de aumentar los ingresos generados por las ventas. Para ello se bajan los precios al reducir los formatos y la composición de la página y se reduce el precio de suscripción gracias a la introducción de la publicidad (Kaenel, 1987, pp. 35-46). La publicidad se convierte de hecho en un medio de financiación de la prensa europea para 1820 (Mattelart, 1995, p. 141). 
nación, se ve a la prensa como vínculo y como una forma de integración social, manteniéndose así el carácter político-pedagógico que la caracterizó. Sin embargo, al crecer el público y diversificarse, se tenderá menos a la constitución de los individuos propuestos por la llustración, esto es, ciudadanos en el libre ejercicio de su razón, que a la constitución de un público consumidor. Se da pie a un principio de integración que no se finca en la construcción de una comunidad de sentido, sino meramente en el mantenimiento de un mercado consumidor de bienes. Esta cuestión se expresará en el paso de una prensa de escritores que enfatizaba la opinión como formadora de ciudadanos, a una prensa comercial, orientada a la estandarización de los criterios de producción noticiosa, para una mayor eficacia en la cobertura de la información y el abatimiento de los costos. ${ }^{11}$

En la medida en que el carácter político-pedagógico fue cada vez menos un debate abierto y más la publicitación de posturas afines a los intereses de los dueños de las empresas periodísticas, se dio lugar a una forma de censura más controlada y sistemática disimulada bajo la ideología de la "objetividad" de la noticia y la "responsabilidad del reportero", y que se impulsaría como parte de las nuevas necesidades de expansión de la industria del periódico. ${ }^{12}$ La construcción de la neutralidad de las técnicas de la comunicación será la condición de su reconocimiento y legitimidad social y política lo que también dará lugar a las relaciones de oposición en el campo periodístico como se vera más adelante.

La actividad periodística tendió pues a especializarse y a generar criterios más homogéneos en la formación del periódico, dando lugar a que el acopio de noticias se constituyera en una de las actividades centrales de la prensa escrita y permitiendo el surgimiento de las agencias de noticias, de los reporteros y de la prensa de entretenimiento. ${ }^{13}$ Asimismo, la transformación de la práctica periodística generó la creciente especialización de las actividades internas del periódico. Se hizo necesario, por ejemplo, diferenciar con claridad una nota informativa de un artículo de

11. En los periódicos esto se hará visible en el desplazamiento paulatino del artículo editorial por la nota informativa.

12. Lo anterior tuvo también consecuencias importantes en lo que refiere a la constitución de un sentido de comunidad gremial entre los periodistas asalariados. Esto es el efecto de cuerpo, de identidad colectiva fundada en el ejercicio de la actividad especifica que les permitía reconocerse entre sí y diferenciarse de aquellos que no compartían o no conocian los principios de constitución de su práctica "objetiva" y "responsable". Para la noción de "efecto de cuerpo" veáse P. Bourdieu, "Effet de champ et effet de corps", Actes de la recherche en sciences sociales, 59, sep. 1985.

13. "Dentro de la construcción de un público 'popular' para la prensa diaria, el folletín desempeña particularmente en Francia el papel que en Estados Unidos corresponderá a los comics a partir de la dácada de 1880. El Folletin hace su aparición en 1836 y es a Eugenio Sue a quien se le atribuye el Folletin en serie" (Mattelart, 1995, pp. 341-345). 
fondo, editorial o de un anuncio publicitario, lo que posibilitó explicitar las reglas de validación de los enunciados propiamente periodísticos, esto es, sus reglas de reconocimiento interno. ${ }^{14}$

De esta manera aparecen los géneros periodísticos, que si bien pudieron inspirarse en los saberes literarios, se constituyeron con base en la necesidad de ampliar el mercado y la venta de los periódicos. Éste acabó transformándose también en instrumento crucial para facilitar la venta de otros bienes y servicios, de manera que la capacidad de obtener réditos estuvo cada vez más vinculada al tamaño y perfil de un público consumidor (Thompson, 1993:357).

La diversificación de la prensa respecto al manejo de los diversos géneros periodísticos dio lugar a la oposición entre los periódicos que ofrecían antes que nada noticias, de preferencia sensacionalistas, y los periódicos que proponían fundamentalmente análisis y comentarios de los expertos y que estarían interesados en marcar su distinción en relación a los primeros. El surgimiento de esta oposición es lo que permite hablar ya de la existencia de campo periodístico propiamente dicho.

El campo periodístico se ordena como el lugar de una oposición entre dos lógicas y dos principios de legitimación: por una parte el reconocimiento otorgado por los pares que reconocen los valores y principios internos de objetividad y neutralidad y, por otra, el reconocimiento externo de la cantidad, materializado por la magnitud de entradas, lectores, audiencias o espectadores en la que la cifra de venta y el beneficio económico es un veredicto de mercado (Bourdieu, 1994:4).

Ya para principios del siglo $\mathrm{Xx}$, el cine y la radio ${ }^{15}$ evidenciaron lo que de hecho la práctica periodística posibilitó en su génesis: la reformulación de los espacios públicos y privados, la modificación de la percepción del mundo por los agentes y los

14. Esta diferenciación dio lugar a la especialización de los agentes que colaboraron en el periódico. Las editoriales y artículos de fondo quedaron en manos de los especialistas en los temas tratados y se constituyeron en las secciones con menos espacio, mientras que las noticias informativas pasaron a manos de los redactores y reporteros, cubriendo, como ya se dijo, la mayor parte del espacio del periódico. De igual manera se modificaron las reglas de valoración de los saberes específicos de los "periodistas". Si el escribir bien se habría constituido en la base de esta actividad, cada vez más se requirió de ciertas competencia técnicas que se fueron desarrollando conforme se tendió a homogeneizar los criterios de producción periodística. Así por ejemplo se generalizó el manejo del esquema estándar de redacción de noticias conocido como "pirámide" y desde una dimensión más técnica, el manejo de la máquina de escribir pasó a ser parte de las competencias para todo aquel que quisiera ser reportero o redactor.

15. En 1985 los hermanos Auguste y Louis Lumiére inventan el cinematógrafo y ya para 1896 se lanzan al mercado los aparatos de proyección que se explotarian comercialmente en ferias y ambulantaje. La primera sala estable se instala en Los Ángeles en 1902 y ya para 1913 están instaladas importantes casas productoras como la Pathe y Gaumont en Francia y Hollywood en Estados Unidos (Mattelart, 1995 , p. 327). El caso de la radio no fue menos vertiginoso, la utilización de la radio a gran escala 
grupos, la constitución de un público, de una audiencia cada vez más hecha bajo la ideología de la racionalidad moderna y, por último, la constitución de los medios en verdaderas industrias de la cultura.

\section{La comunicación como práctica simbólica}

Se dice que la modernidad, y con ello la constitución del sujeto moderno, teniendo como marco la ideología del liberalismo económico, está fundada en un proceso lento pero irreversible que comprende, entre otras cosas, el paso de una sociedad tradicional basada en la comunidad, a una sociedad racional, constituida por vínculos impersonales y contractuales a gran escala que facilitan la composición del mercado como espacio de flujos de intercambio. La modernidad supuso pues el tránsito y construcción de nuevas reglas de socialización e identificación.

En su devenir, la modernidad supuso también la redefinición del espacio político con la reconfiguración del Estado y sus poderes. Con la institución del Estado moderno la sociedad se convierte en el ámbito legítimo de las relaciones sociales, posibilitando que se erija el principio de la legitimidad política en la noción de "soberanía popular". 16

Lo anterior hizo necesario, e inevitable, que se generara un principio de reconocimiento de la voluntad y de la libertad política de los agentes, pero también el reconocer la existencia efectiva de las "muchedumbres desarraigadas", lo que implicaba la necesidad de trabajar con ellas por cauces que permitieran poner en

comienza en la década de los veinte, la primera estación comercial fue lanzada por la Westinghouse en noviembre de ese año, ya para 1922 más de 500 estaciones habían obtenido licencia en los Estados Unidos. Estas primeras estaciones y sus organizaciones matrices obtuvieron sus ingresos de la venta de transmisores y receptores, así como de vender tiempo al aire a difusores y anunciantes y por concesionar programas a través de las redes de estaciones (Thompson 1993, p. 202). Así pues, a diferencia de la prensa, tanto el cine como el radio se incorporan desde su nacimiento a los circuitos del mercado, lo que pautaría de manera decisiva su desarrollo.

16. Al hablar de soberanía popular y por tanto de "pueblo", se reconocen en principio dos momentos indisociables en su constitución: aquél que lo remite no a una población, sino a un principio político, la ideología liberal, que posibilita la aparición del Estado Moderno como representante de la voluntad de todos. En esta concepción la voluntad de todos ya no es Dios, sino la Ley. El pueblo es la voluntad que se hace ley y el Estado ese guardián de la ley para todos. El Estado puede entonces justificar su principio de legitimidad en el "pueblo" y, mediante la ley, su autoridad sobre él (sobre la noción de "soberanía popular" véase Mairet y Chatelet, Chatelet, 1981, Tomo III). Un segundo momento estaría referido no al principio de voluntad, sino al de racionalidad, esto es, a la atribución de la razón que permite delegar la capacidad de actuar en el Estado. "El pueblo" no es sólo un principio, sino una realidad empírica que se objetiva en las relaciones sociales entre individuos y grupos concretos. 
común el ejercicio individual de la propiedad y la voluntad política. Se requirió también entonces de la existencia de "ciudadanos"17 en el libre ejercicio de su razón, y para lograrlo se postuló la necesidad de una economia del lenguaje que permitiera organizar el consenso sobre los derechos y las prescripciones de estos ciudadanos.

Es pues en la recomposición de los principios económicos, políticos y sociales que se hace evidente la necesidad de objetivar las formas de organización y circulación de los significados sociales conformándose así las condiciones de emergencia de la comunicación como una práctica simbólica diferenciada.

Bajo estas condiciones la comunicación aparece como el ejercicio estratégico del lenguaje que permite objetivar las nuevas formas de organización y circulación de los significados sociales. La comunicación se entiende entonces como una pedagogía, una técnica "civilizatoria" de cuerpos y almas, surgida de la necesidad de construir el "sensus communis", la puesta en común de los valores y creencias de la sociedad moderna. ${ }^{18}$ Puesta en común que, por otro lado, bajo los principios del hombre natural y la razón, desprendidos del pensamiento liberal, supondrá menos la relación de acción recíproca — como después se le ha querido ver-que la edificación del principio de esquemas comunes del juicio y del gusto, fundados éstos en el libre albedrío. La comunicación aparece asociada a los procesos de formación de los sujetos de acciones morales. ${ }^{19}$

La comunicación como pedagogía emerge claramente, por un lado, en la aparición de la instrucción pública como parte da la formación del carácter cívico de los agentes en los principios de la racionalidad moderna. La instrucción pública se convertirá entonces en un verdadero campo de producción y conservación simbólica

17. El ciudadano es, en esta óptica, miembro del "pueblo soberano", sujeto de derechos y obligaciones, se somete a la ley que se "da" así mismo y a causa de ella obedece al Estado, pero supone el exigir el cumplimiento de esa ley. El ciudadano se formula así en la ideología del pueblo: "hombre libre en el estado" (Gerard Mairet, 1981, p. 129).

18. Ejemplos que pueden ser ilustrativos en este punto son la adopción del sistema métrico decimal y los usos horarios de Greenwich en tanto que formas de objetivar la transformación que se da en la medición del tiempo y el espacio y su unificación nacional y después mundial. Al respecto Armand Mattelar señala: "Producto de la ilustración, del ideal igualitario de todos ante la ley, el proceso intelectual de abstracción encarnado por las medidas fue presentado por sus iniciadores como símbolos de la unidad nacional y del progreso" y más adelante citando al historiador polaco de pesas y medidas Witolda Kula, en relación al sistema métrico decimal, Mattelart señala "gracias a este sistema se ha logrado imponer a la nación las mismas categoría de pensamiento, representación espacial, ideas novedosas sobre pesas y medidas, imponer a los hombres las mismas categorias de pensamiento con el fin de comprenderse mejor" (Mattelart, 1995, p. 68).

19. No se habla aqui de lo que frecuentemente se designa con el vocablo de "moral burguesa"; se trata de una antropología moral y política, es decir, de un sistema de valores éticos, en este caso referidos a los constituidos por el liberalismo. 
donde los agentes sociales concretos incorporan los esquemas de reconocimiento de la legitimidad del discurso social común.

Pero por otro lado, también aparecerán los "expertos" quienes, al poder publicitar - en el sentido que Habermas da a la acción de hacerlo público- sus discusiones, hacen posible que las cuestiones debatidas se conviertan en algo "general", no sólo en el sentido de su relevancia, sino también de su accesibilidad (Habermas, 1981:74). Se logra entonces la constitución de interlocutores, de destinatarios racionales capaces de manifestarse respecto a aquello que tienen ante sí y emitir un juicio. Los filósofos, juristas, economistas, médicos y sacerdotes asumen este papel de "educadores" de este "público" aún difuso, pero potencialmente interesado. Es importante señalar, sin embargo, que ninguno de estos "expertos" se reconoce como lo que hoy denominamos "comunicadores"; no obstante, ahora, desde la contemporaneidad, se puede decir que allí se encuentran las huellas del surgimiento de una dimensión completamente distinta al ejercicio puramente expresivo del lenguaje.

Así pues, tanto la institución escolar del Estado-Nación como los expertos posibilitan la aparición de un "público", de lectores y espectadores, que fue extendiéndose en la medida que el desarrollo del capitalismo exigió una conducta racionalmente cada vez más orientada a la información. ${ }^{20}$

La construcción del carácter cívico, aunada al desarrollo tecnológico, industrialización, poblamiento y urbanización que dieron lugar a la concepción política de lo "público", permiten que la comunicación pase de ser la pedagogía política de un auditorio todavía difuso y sujeto a las condiciones impuestas por los procesos de exclusión escolar, de la circulación relativamente restringida de materiales impresos y la relación cara a cara en un local físico compartido, a ser una verdadera técnica simbólica, a escala, de la formación social. Técnica que tendrá su manifestación concreta en el proceso de racionalización e instrumentalización de la actividad hablar/publicitar, que se expresará en la conformación de la prensa como campo de producción y reproducción simbólica.

20. Esta dimensión pedagógica de la comunicación de hecho es parte de la aparición del "ámbito de lo público", que hizo posible la publicitación de estos juicios expertos, y que en mucho es impulsada por la constitución del mercado. "En la medida en que las obras filosóficas y literarias, las obras artísticas en general comenzaron a ser producidas para el mercado y mediadas por él, comenzaron a ser 'universalmente' accesibles. Este proceso que lleva a la cultura a convertirse en una forma mercantil, en su calidad de obra, la hace por vez primera una cultura capaz de discusión y controversia; y hace posible la formación de un otro destinatario (lector, oyente, espectador)" (Habermas, 1981, pp. 74-75). 


\section{La comunicación como ideología y objeto de estudio}

Si la comunicación surge en su constitución como práctica simbólica ilustrada, ya en el caso periodístico, no se consolida sino hasta que se instituye como una ideología y esto será posible cuando se instaura como saber legítimo avalado por el campo académico.

Lo anterior fue facilitado por el interés que suscitó la aparición de los medios electrónicos (cine, radio y posteriormente la televisión). Pensar la comunicación desde los nuevos medios creó un espacio común de reflexión donde convergen distintas disciplinas. La psicología, sociología, antropología, filosofia y lingüística nombraron "comunicación" a una dimensión de sus respectivas preocupaciones científicas, y desde ahí operaron sus instrumentos tẹóricos y metodológicos para entenderla y explicarla.

Los debates en torno a la forma de abordar los fenómenos comunicativos, la manera en como se construyó teóricamente estos problemas, los énfasis distintos, los desplazamientos en la comprensión de los medios en su compleja relación con los agentes y los grupos, así como su uso comercial, marcaron el camino por el que la comunicación devino en objeto de estudio científico; generaron las condiciones de su emergencia como saber disciplinario; y proveyeron de un pretendido estatuto de cientificidad al que se apelará posteriormente al ser reconocido como saber experto.

El contexto político mundial expresado, entre otras cosas, en la redefinición de las zonas de influencia y el estallamiento de las dos guerras mundiales preparó las condiciones para que, junto con la avidez de la naciente industria masmediática por explorar lo que sabía su condición de existencia: el público, proliferaran las investigaciones sobre la comunicación en la primera mitad del siglo $\mathrm{xx}^{21}$

Ya para la década de los cuarenta, este campo de reflexión se vió crecientemente legitimado, fundamentalmente en los Estados Unidos, al contar para entonces con numerosos centros de investigación dirigidos por académicos con reconocidas trayectorias en sus respectivas disciplinas. ${ }^{22}$ Ahí los diversos estudios sobre los medios y propaganda política contaban con un lugar preponderante, con importantes recur-

21. "Para los historiadores de esta corriente, el comienzo de la Masss Communication Research se remonta a la publicación, en 1927, de la obra del polítologo Harold Lasswell, Propaganda Techniques in the World War...; esta obra, fiel a la perspectiva conductista, es representativa del espiritu de la época, dibuja el perfil de un público objetivo que obedece ciegamente al esquema estímulo-respuesta" (Mattelart, 1995, p. 365).

22. El ya mencionado politólogo Harold Laswell, Kurt Lewin (psicólogo), Carl Hovland (psicólogo), Pau] Lazarsfeld (sociólogo), Robert K. Merton (sociólogo), son algunos de los nombres de estos investigadores que abordaron la problemática de la comunicación, contribuyendo al auge de la investigación sobre el tema. 
sos provenientes tanto de instituciones públicas como privadas; así como con la aparición de diversas publicaciones que permitieron que estos estudios fuesen publicitados en amplios sectores exclusivos del campo científico y académico. ${ }^{23}$

Las condiciones económico-políticas que permitieron el auge de la investigación sobre los fenómenos comunicativos, así como las bases teóricas y metodológicas en las que estos estudios se inspiraron, tendieron a legitimar y consolidar una postura: el instrumentalismo empirista que, considerando a los medios masivos de comunicación como el objeto de estudio por excelencia, acabó por enaltecer la dimensión técnica antes que pedagógica de la comunicación, reduciéndola a un esquema científico totalista y procesual de flujo circular, más que a un relación interactiva y cultural. Bajo estos parámetros se generó asimismo todo un metalenguaje convencional que dominará, hasta la fecha, las descripciones comunicativas (emisor, mensaje, receptor, audiencia, canal, etcétera). ${ }^{24}$

De esta forma, ante la estrecha vinculación entre la investigación, los organismos públicos y privados, y las industrias masmediáticas, se tendió a resaltar la aplicabilidad técnica de los resultados de las investigaciones, tanto en el campo político como el comercial, haciendo que la comunicación se identificase con el funcionamiento de los medios y afianzado así la visión instrumental sobre ella en su difusión y en su uso. Pero el devenir de la comunicación como objeto de estudio ya había sido allanado para su incorporación en el discurso social científico y profesional.

El auge de la investigación sobre comunicación así como su publicitación a través de revistas especializadas y de divulgación abrieron la posibilidad de pensar a los medios, bajo la óptica del paradigma empirista dominante, no sólo en relación con la

23. De entre todas cabe destacar la aparición en 1937 de la Revista The Public opinion Quarterly, editada por la Universidad de Princeton, concretamente por la "School of Public Affairs". En 1947 se crea la World Association for Public Opinion Research y la International Communication Research al interior de la American Association for Public Opinion Research; asi mismo se desarrollan los centros de Stanford, Columbia, MIT e Illinois. En 1950 se crea el Journal of Communication financiada por la National Society por the Study of Communication y editada por la Universidad de Illinois. A mediados de los cincuenta se da la enorme proliferación de los "Readers", recopilaciones de artículos de "vanguardia" que circulaban por diversas instituciones publicas y privadas (Moragas, 1981, pp. 29 42).

24. Es importante destacar no obstante que junto a estos estudios de corte empirista y comercial se dieron investigaciones que poco se conocen en el ámbito comunicativo. Así en la escuela de Chicago se dieron algunas posturas partidarias de una sociología empirica pero cualitativa. Esta tendencia tuvo como uno de sus principales representantes a R. E. Park, quien investigó cuestiones de inmigración y de la integración de los inmigrantes a la sociedad norteamericana y sobre la formación de los guetos étnicos (cfr. Mattelart, 1995, pp. 367). Por otra parte se dieron también las más conocidas aportaciones de la denominada "Escuela de Frankfort", de corte más crítico y especulativo y que tendrán una enorme influencia para la reflexión sobre la comunicación para la década de los sesenta. 
Modernidad, globalización y la emergencia de la comunicación

política doméstica sino también como un recurso privilegiado para encarar los procesos de descolonización territorial a nivel internacional y, desde la óptica opuesta para impulsar el "desarrollo" económico y cultural de los países emergentes o "atrasados". El creciente reconocimiento social de los investigadores que se identificaban así mismos como "expertos" en comunicación de masas y su incorporación como asesores en organismos de carácter nacional e internacional permitió incluir en las agendas de estos organismos el tópico de la comunicación. ${ }^{25}$

Por supuesto que detrás de las discusiones y propuestas de estos organismos estarian mediando los postulados de las teorías de la ciencia política norteamericana de la posguerra que habían ya imaginado todo un proyecto de "ingeniería social" fundado en toda una filosofía del desarrollo: el "Nation Building", la creación de Naciones-Estado viables capaces de actuar efectivamente en el mundo moderno, un mundo democrático y competitivo. ${ }^{26}$ Bajo esta concepción, la fragmentación y la desintegración de las sociedades en desarrollo podrían explicarse como el resultado de la coexistencia de tensiones constantes entre la modernidad, estabilidad, racionalidad y tradicionalidad. ${ }^{27}$

Para resolver estas tensiones este pensamiento otorga un papel casi mistificador a la cultura política, la educación y singularmente la comunicación. Esta última, avalada por los estudios e investigaciones mencionados en su momento, se constituye en la bóveda totalizadora entre cuyos flujos de emisión, recepción y feedback, adquirirían cohesión y forma las sociedades en desarrollo (Orozco, 1978:388-392).

Para Pye, por ejemplo, los procesos básicos de modernización y desarrollo nacional pueden concebirse como problemas de comunicación, sobre todo si se entiende, como él lo hace, que los problemas del desarrollo económico se hallan indefectiblemente vinculados a todos los aspectos de la vida en las sociedades en "transición", entre ellos el político. "Los medios de comunicación - nos dice este autorofrecen una base común para el análisis de los más evidentes problemas

25. En 1958 las Naciones Unidas lanzaron la idea de impulsar el estudio de la comunicación de masas, en 1966 la propuesta se cristaliza con una recomendación formal de la Asamblea General de las Naciones Unidas para que los gobiernos potencien sus sistemas de comunicación masiva (Moragas, 1981, 66).

26. José Luis Orozco señala que para esta concepción "el asunto estribaría en mostrar las formas para desarrollar simultáneamente un sistema democrático de rectorazgo político y una 'sociedad nacional viable' para el logro de nuevos estándares de vida social y económica dentro de los marcos de la democracia política" (1978, p. 373).

27. La ideología del desarrollo, "la modemización", surge avalada por las investigaciones realizadas desde principios de los cincuenta fundamentalmente en la Universidad de Princeton, teniendo entre sus más destacados promotores gentes como Almond, Pye, Coleman, Hyman, Lerner, Rostow, Apter, entre otros. 
estructurados y de las más sutiles cuestiones de actitudes y valores en el proceso total de los cambios políticos y de la forma de una nueva nación" (Pye, 1969:16).

El sentido de estas proposiciones sugiere también muchas de las bases sobre las que se funda la ideología que tanto influyó en la fundación de la Comunicación en los inicios de la modernidad europea occidental. Pero fundamentalmente genera las condiciones para que la comunicación se reconozca como un verdadero símbolo de la modernidad y se constituya como un referente obligado en el esquema de las relaciones mundiales tanto económicas, como políticas y culturales.

\section{Fin de siglo: globalidad y comunicación}

Según Eduardo Andión las posibilidades inscritas en la dimensión tecnológica de los medios de comunicación, por su capacidad de cambiar de escala los procesos tradicionales de difusión, reproducción e incluso de creación de las estructuras culturales, dan la idea de que pueden condicionar de manera distinta los principios y efectos de los procesos de socialización en las sociedades modernas. Por eso el fenómeno de la modernización adquiere en la doxa ${ }^{28}$ comunicológica el carácter de mito fundador, y bajo cierta mirada, principio legitimador de la profesión de comunicológo, puesto que este principio es capaz de operar aún en los casos en que se encauza a recuperar y hacer circular la historia y lo popular tradicional (memoria colectiva) en la cultura masiva, tanto como forma de renovación como de distinción (Andión, 1995:27-28).

Así pues, al fin del siglo, cuando las sociedades se apoyan crecientemente en los nuevos dispositivos de la comunicación electrónica, la Comunicación va apareciendo cada vez más como verdadero paradigma de una contemporaneidad caracterizada por la mundialización de la economía, la unificación de los mercados y la mediatización de la sociedades.

La comunicación aparece entonces como un verdadero dispositivo de tecnologías simbólicas para la organización social, al que se le atribuye la capacidad de lograr, incluso, el equilibrio y armonía del grupo humano. Es decir, se constituye en una verdadera sociodicea, uno de cuyos ejemplos es la aplicación de la comunicación organizacional en las empresas para instituir identidades restringidas que favorezcan el incremento de la productividad.

28. Para Pierre Bourdieu la "doxa" refirere al sentido común ordinario de los agentes, al universo de lo indiscutible inscrito como parte de su incorporación del mundo (cfr. Bourdieu, 1979, pp.159-171). 
Modernidad, globalización y la emergencia de la comunicación

Uno de los más fervientes defensores de las posibilidades abiertas por la sociedad de la comunicación y la tecnología telemática, Gianni Vattimo, ha escrito que si a la imagen estallada del mundo que nos presenta la ciencia se le extiende "a la esfera de la comunicación social, que se ha desarrollado gracias a la prensa, a la radio, a la televisión y a todo lo que se agrupa bajo el nombre de telemática, se entendería mejor lo que Heidegger pensaba acerca de la posibilidad de que el Ge-Stell (Composición como esencia de la técnica) preparase una superación de la metafísica mediante la disolución sujeto-objeto que ha dominado la modernidad"' ${ }^{29}$

No obstante, si bien la condición moderna de la comunicación la hace aparecer como dispositivo que integra la fragmentación, esta condición es la que también la opone, como antes señale, al proyecto de la Ilustración que la posibilita y la proyecta. En su velocidad de expansión y circulación de los bienes simbólicos, la comunicación vincula pero también fragmenta, expande pero también aísla. Y en eso reside su principal contradicción. Su condición moderna la instituye como gran relato en el momento en cada vez más la propia comunicación puede hacer ver más claramente la pluralidad de los relatos, cuando puede hacer ver la verdad como una ficción aceptable para ciertas comunidades de interpretación, lo que trae como consecuencia más sobresaliente la extrema multiplicación de las narraciones que convocan a la comunidad de los individuos (Lyotard, 1984:109-119).

La comunicación se instituye así como condición necesaria de un devenir social marcado por la aceleración de los cambios en la tecnología, en la estructura económica, en la configuración de los circuitos de consumo. La comunicación adquiere un valor estratégico en la interconexión del mundo que la visión instrumental, producto de la modernidad, insiste en glorificar sin reparar en las profundas desigualdades que ahí se engendran.

29. "La teología de la información" en La Jornada semanal No. 62, 1996. Vattimo ha sido uno de los pensadores que ha insistido, siguiendo a Heidegger, que la relación entre las ciencias humanas y la actual sociedad de la comunicación (intensidad de las transacciones informativas y proclividad a identificar acontecimiento y noticia), "es mucho más estrecha y orgánica de lo que normalmente se cree... El ideal de autotransparencia que asigna a la comunicación social y a las ciencias humanas un carácter no sólo instrumental sino de alguna manera final y substancial, en el programa de emancipación, se redescubre hoy por todas partes en la teoría social" (Vattimo,1990, p. 98). 


\section{Bibliografía}

Andión, Eduardo (1995), "La transformación de los campos de producción cultural: una aproximación a la experiencia de los comunicadores y los comunicologos", Foro Departamental de Educación y Comunicación. UAM, México.

Bourdieu, Pierre (1994), "L'Emprise Du Journalisme", en Actes de la Recherche en Sciences Sociales, n. 101/102.

- (1990), Sociología y Cultura, Grijalbo/Conaculta, México.

(1979), Outline of a Theory of Practice, Cambridge University Press.

(1977), " Sur le Pouvoir Symbolique", en Annales, Economie, Societés, Civilisations, n. 3, mayo-junio (traducción inédita de Rosa Ma. Aponte, Departamento de Educación y Comunicación, UAM-X).

Chatelet, Francois (1981), Historia de las ideologias, t. III, Premiá Editorial, México. De Moragas Spa, Miquel (1981), Teorías de la comunicación, Gustavo Gili, Barcelona, España.

Dreyfus H. y P. Rabinow (1988), Michel Focault: más allá del estructuralismo y la hermenéutica, UNAM.

Giddens, A. ( 1993), Consecuencias de la modernidad, Alianza Universidad, Madrid.

Echeverría, J. (1995), Cosmopolitas domésticos, Anagrama. Madrid, España.

Habermas, Jürgen (1981), Historia y critica de la opinión pública (1962), Gustavo Gili. Barcelona, España.

(1985), El discurso filosófico de la modernidad, Taurus Madrid.

Horkheimer M. y W. Adorno (1970), Diálectica del Iluminismo. Ed. Sur. Buenos Aires.

Kaenel, Philippe (1987), "Le Plus Illustre des Illustrateurs: le cas Gustave Doré (1832-1883)", en Actes de la Recherche en Sciences Sociales, n.66/67.

Lyotard, J. (1984), La condición posmoderna, Cátedra, Madrid.

Mattelart, A. (1995), La invención de la comunicación, Siglo XXI, México.

Orozco, Jose Luis (1978), La pequeña ciencia, FCE. México.

Pye, Lucian (1969), Evolución política y comunicación de masas, Troquel, Buenos Aires.

Thompson, J. B. (1993), Ideologia y cultura moderna. Teoría y crítica social en la era de la comunicación de masas, UAM-X, México.

Touraine, A. (1994), Critica a la modernidad, $\mathrm{FCE}$, Argentina.

Vattimo, G. (1990), La sociedad transparente. Paidós, Barcelona. (1996), "La teología de la información", La Jornada semanal n. 62. 